\title{
An Extended Gate Field Effect Transistor (EGFET)-based pH Microsensor Utilizing a Polypyyrole Coated pH Microelectrode
}

\author{
Mustafa Şen ${ }^{a, \times x}$, Fikri Seven ${ }^{b}$ \\ ${ }^{a}$ Department of Biomedical Engineering, Izmir Katip Celebi University, Izmir, Turkey. \\ ${ }^{b}$ Department of Biomedical Engineering, Izmir Katip Celebi University, Izmir, Turkey.
}

\section{ARTICLE INFO}

\section{Keywords:}

EGFET $\mathrm{pH}$ microsensor

MOSFET

pyrrole

ultra-micro electrode

\begin{abstract}
A B S T R A C T
Here, an ultra-small size, simple and inexpensive metal oxide semiconductor field effect transistor (MOSFET)-integrated needle type EGFET $\mathrm{pH}$ microsensor was fabricated. The EGFET $\mathrm{pH}$ microsensor has the potential to be applied to fast and precise local $\mathrm{pH}$ measurements. The system was composed of two components; a pH sensitive probe and a MOSFET. The $\mathrm{pH}$ sensitive probe wasmade by electrochemically coating the surface of a Pt ultra micro-electrode with polypyrrole, a semiconductor polymer. The $\mathrm{pH}$ sensitive probe was then integrated with the gate of the MOSFET to carry out measurements in PBS at different $\mathrm{pH}$ values. The real time response of the EGFET $\mathrm{pH}$ microsensor was also tested by cycling the probe in three solutions at different $\mathrm{pH}$. The results showed that the developed $\mathrm{pH}$ microsensor is sensitive to $\mathrm{pH}$ change. It is expected that the EGFET $\mathrm{pH}$ microsensor will allow local $\mathrm{pH}$ analysis in biological samples or corrosion studies.
\end{abstract}

\section{Introduction}

Microelectrode probes are used in local measurements and electrochemical imaging in many different areas such as corrosion [1], single cell studies [2] and measurement of neurotransmitter release [3]. There are various studies in the literature on the fabrication of such type of microprobes that allow local $\mathrm{pH}$ measurement. The fact that traditional measurement methods such as glass $\mathrm{pH}$ electrodes could not be miniaturized for the application at the desired level in micro scale led to the production of these micro probes with new approaches. Generally, pH microprobes have disadvantages such as limited $\mathrm{pH}$ measurement range, long response time for meaningful signal, and sensitivity. $\mathrm{H}+$ ion selective field effect transistors (FET) [4], optical pH sensors [5] and microelectrode $\mathrm{pH}$ sensors [6] are more outstanding examples and have been used successfully in certain studies in the literature. Although ion-selective FET (ISFET) based $\mathrm{pH}$ sensors are relatively easy to miniaturize, they have disadvantages such as low sensitivity and long signal stabilization time. Optical pH sensors do not need a reference electrode and can successfully detect the spatial distribution of $\mathrm{H}+$ ions in sea water [7]. However, since such sensors can be severely affected by the color of the solution, they are used in almost colorless solutions whose transparency does not change significantly for an accurate result. Microelectrodes are considered powerful tools for in vivo or on-site measurements in various fields such as physiology, microbial ecology, medicine, neuroscience, and environmental monitoring. In the literature, there are various studies on the effective use of glass $\mathrm{pH}$ microelectrode $\mathrm{pH}$ sensors in local $\mathrm{pH}$ measurement due to their advantages such as high selectivity, reliability and wide dynamic range. These types of $\mathrm{pH}$ sensors are mostly used as scanning electrochemical microscopy (SECM) probe and due to the structure of this microscope, these probes can display local $\mathrm{pH}$ distributions. In this study, an ultra-small size, simple and inexpensive EGFET $\mathrm{pH}$ microsensor has been fabricated with a new approach. In short, the EGFET $\mathrm{pH}$ microsensor was developed by integrating a metal oxide semiconductor FET (Metal Oxide Semiconductor Field Effect Transistor - MOSFET) and a Pt ultramicro electrode (UME) coated with a semiconductor polymer, polypyrrole. The EGFET $\mathrm{pH}$ microsensor was designed for fast and precise local $\mathrm{pH}$ measurement. It is anticipated that the EGFET $\mathrm{pH}$ microsensor can be used for local $\mathrm{pH}$ measurement in small-volume environments, biological samples or corrosion studies.

\section{MATERIAL AND METHOD}

\subsection{Material}

Phosphate buffered saline (PBS) (Sigma Aldrich, USA), $\mathrm{NaOH}$ (Sigma-Aldrich, USA), HCl (Sigma-Aldrich, USA), pyrrole (Sigma-Aldrich, USA), Ag paste (Sigma-Aldrich, USA), n-type MOSFET (IRFZ44N, International Rectifier, USA), Pt wire (Sigma-Aldrich, USA), glass capillary tube (World Precision Instruments, USA).

\subsection{Fabrication of $P t$ ultramicroelectrodes (Pt-UME)}

Platinum microelectrodes can be fabricated in various ways and in this study, it was fabricated by inserting a Pt wire into the glass capillary tube $[8,9,10,11,12,13]$. Pt wire, with a diameter of $25 \mu \mathrm{m}$, was connected to a copper wire covered with an open non-conductive material before this process, so that the $\mathrm{Pt}$ wire could be easily placed inside the single glass capillary tube. For the bonding process, the $\mathrm{Pt}$ and $\mathrm{Cu}$ wires were bonded to each other by using silver $(\mathrm{Ag})$ paste and then the connection was made permanent by the solidification of the silver paste at $180^{\circ} \mathrm{C}$. Next, the Pt wire was placed inside the single glass capillary tube with 


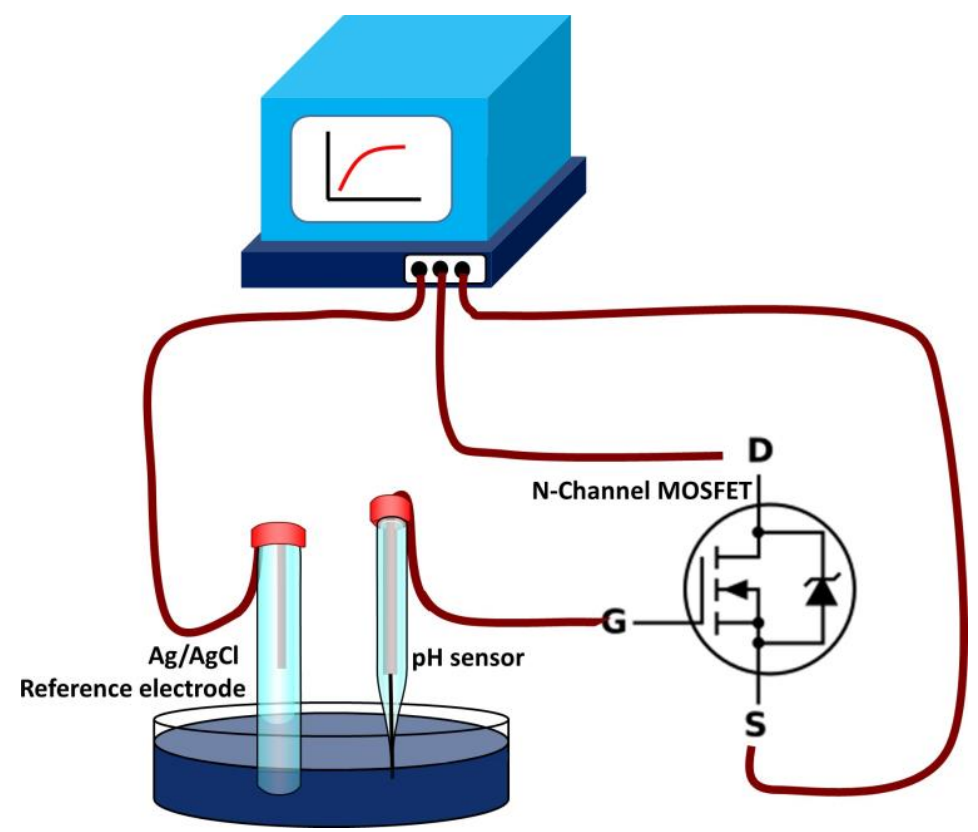

Figure 1: EGFET pH microsensor constructed through the integration of a polypyrrole coated Pt microelectrode and a MOSFET

the help of the copper wire to which it was fixed, and the glass capillary tube was pulled over the Pt wire with a micropuller (PC-10, Narishige, Japan) machine. With the help of a "microforge" (MF-830, Narishige, Japan) machine, the gap between the glass and the Pt wire was removed and the probe was produced in a leak-free manner. Finally, by grinding the tip of the probe using a micro grinder (Microgrinder, Narishige, Japan), the excess Pt wire in the probe tip was removed from the environment and the electrode was produced as a micro-disc.

\subsection{Deposition of $\mathrm{pH}$ sensitive polymer on Pt-UME}

The surface of the Pt-UMEs produced in this section is covered with a semiconductor polypyrrole polymer by electrochemical deposition method. Cyclic voltammetry was used for coating the polymer. Briefly, the potential applied to Pt-UME immersed in $0.1 \mathrm{mM}$ pyrrole solution was scanned 4 times between 0 and $+0.8 \mathrm{~V}$ (vs. $\mathrm{Ag} / \mathrm{AgCl}$ ). [14].

\subsection{Use and characterization of EGFET pH microsensor in pH measurement after integration with MOSFET}

The $\mathrm{pH}$ measurement capacity of the microprobes using FET analysis unit (B2901A Precision Source / Measure Unit) was demonstrated and characterized in solutions with different $\mathrm{pH}$ values. The source and drain of the n-type MOSFET field effect transistor used for measurement are connected to the source and drain inputs of the FET analysis unit, while the gate part is connected to the produced EGFET $\mathrm{pH}$ microsensor (Figure 1). The $\mathrm{pH}$ measurement was carried out in the presence of $\mathrm{Ag} / \mathrm{AgCl}$ reference electrode to make the measurement more precise and stable. The
$\mathrm{pH}$ sensor and $\mathrm{Ag} / \mathrm{AgCl}$ reference electrode components of the prepared system were immersed in solutions with different $\mathrm{pH}$ values and measurements were carried out. I-V curves were obtained for measurement. Briefly, while applying a constant potential $(+1 \mathrm{~V})$ to the gate, the potential applied between the source and the drain was scanned in a wide range (from 0 to $+1 \mathrm{~V}$ ). The sensitivity of the $\mathrm{pH}$ sensor fabrication after the characterization process was determined and its measurement capacity was displayed in different solutions. The basic starting point here is that the polymer, which is sensitive to $\mathrm{pH}$ change, causes changes in the curves obtained by manipulating the effect of the potential applied to the gate on the channel in solutions with different $\mathrm{pH}$ values. Measurements were carried out in PBS solutions with $\mathrm{pH}$ values of 2, 4, 6, 8 and 10 . The time-dependent change is very important in terms of displaying the potential of the produced $\mathrm{pH}$ sensor, especially in $\mathrm{pH}$ monitoring as SECM probe. At this point, the EGFET $\mathrm{pH}$ microsensor was cycled between three solutions at different pHs (4.68, 6.8 and 9.5).

\section{Results}

Pt-UMEs have been successfully fabricated using the proposed technique. Pt-UMEs were characterized electrochemically before use in the micro-pH sensor. The CV curves obtained from 0 to $+0.5 \mathrm{~V}(\mathrm{Ag} / \mathrm{AgCl})$ in $1 \mathrm{mM}$ $\mathrm{FcCH} 2 \mathrm{OH}$ solution were found to be compatible with the theoretically obtained data, and therefore it was concluded that these probes produced were leak-proof and could be used in numerical analysis. The CV curve obtained during polypyrrole coating was also as expected, and the current value obtained at $+0.8 \mathrm{~V}$ after each coating showed a decreasing trend. The produced Pt-UME was connected to an 

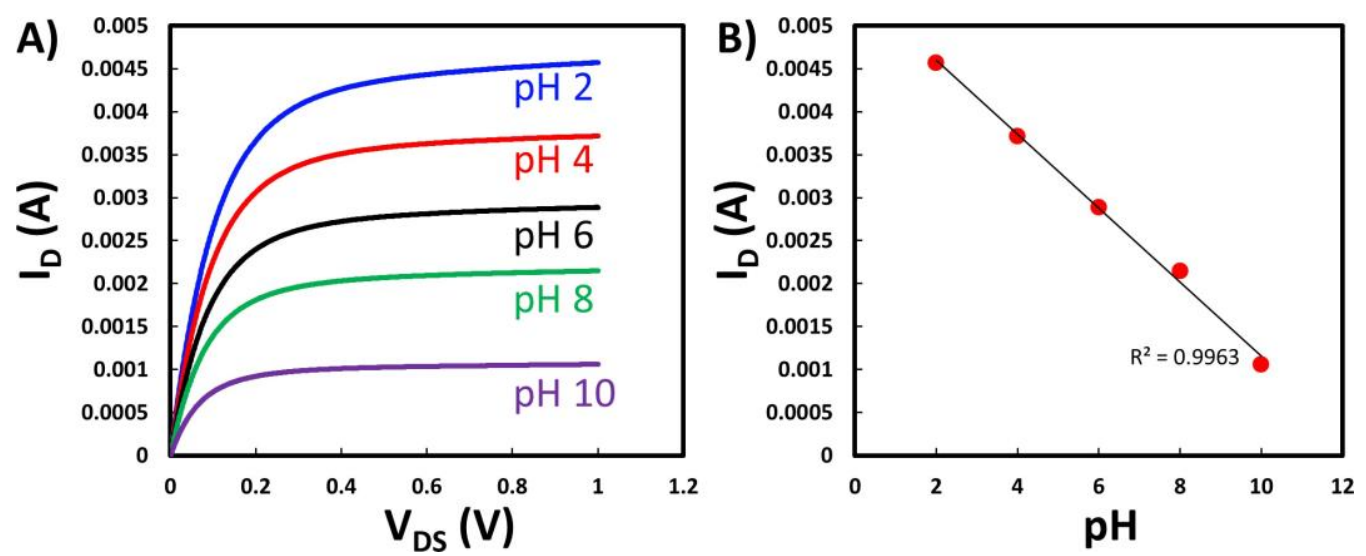

Figure 2: I-V curves obtained at different $\mathrm{pH}$ values $(\mathrm{A})$. Calibration curve $(\mathrm{B})$ obtained using $I_{D}$ values measured at $+1 V_{D S}$ for each $\mathrm{pH}$ level.

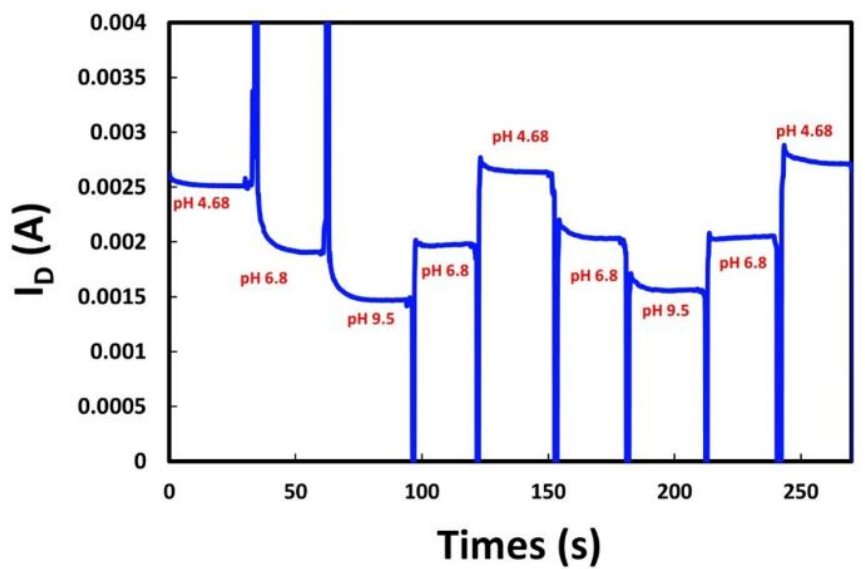

Figure 3: The real-time $I_{D}$ response of the EGFET $\mathrm{pH}$ microsensor at $+1 V_{D S}$ and $V_{G S}$ when cycled between in PBS solutions at pH 4.68, 6.8 and9.5.

n-type MOSFET as shown in Figure 1 and I-V curves were taken in PBS solutions with different $\mathrm{pH}$ values. As seen in Figure 2A, the obtained I-V curves differed depending on the $\mathrm{pH}$ of the solution being measured. The change in the conductivity of the semiconductor polypyrrole at different $\mathrm{pH}$ has modulated the potential applied to the channel between the source and the drain in the MOSFET. This situation resulted in obtaining different I-V curves at different $\mathrm{pH}$ values. The calibration curve based on $I_{D}$ values obtained in different $\mathrm{pH}$ solutions at $+1 \mathrm{~V}_{\mathrm{DS}}$ shows that the relationship between $\mathrm{pH}$ and $\mathrm{I}_{\mathrm{D}}$ is linear $\left(R^{2}=0.9963\right)$. The sensor had a pH sensitivity of $0.4 \mathrm{~mA} / \mathrm{pH}$. When the EGFET $\mathrm{pH}$ microsensor was cycled in solutions at different $\mathrm{pHs}(\mathrm{pH} 4.68$, 6.8 and 9.5), the $\mathrm{I}_{\mathrm{D}}$ response gained a steady state in a matter of seconds. The hyteresis was calculated to be $0.06 \mathrm{~mA}$. These result prove that the response of EGFET $\mathrm{pH}$ microsensor in relatively wide range of $\mathrm{pH} 2$ to 10 is accurate. Microelectrodes have several advantages over traditional macroscale electrodes, such as fast response, high current density, high signal-to-noise ratio, low i-R drop, small double layer capacitance. Microelectrodes are considered powerful tools for in vivo or on-site measurements in various fields such as physiology, microbial ecology, medicine, neuroscience, and environmental monitoring. In the literature, there are various studies on the effective use of glass $\mathrm{pH}$ microelectrode $\mathrm{pH}$ sensors in local $\mathrm{pH}$ measurement due to their advantages such as high selectivity, reliability and wide dynamic range [15]. This type of $\mathrm{pH}$ sensors are mostly used as scanning electrochemical microscopy (SECM) probe and can display local $\mathrm{pH}$ distributions with these probes due to the structure of this microscope. izquierdo2013potentiometric. Electrochemical signals in SECM experiments are very sensitive to tip-substrate separation [16] and $\mathrm{pH}$ measurement in smaller scales requires a very precise control of the probe position. The biggest handicap of microelectrode $\mathrm{pH}$ sensors is their short lifetime and for that they are mostly used in the analysis of biological samples [17]. It is thought that the present EGFET $\mathrm{pH}$ microsensors have a high potential of use in areas where local analysis is important, especially in tissue engineering and single cell studies. 


\section{Acknowledgement}

This study was carried out as a part of the project numbered 2017-ÖDL-MÜMF-0010, supported by İzmir Katip Çelebi University Scientific Research Projects.

\section{References}

[1] K. Fushimi, Y. Takabatake, T. Nakanishi, and Y. Hasegawa, "Microelectrode techniques for corrosion research of iron," Electrochimica Acta, vol. 113, pp. 741-747, 2013.

[2] Y. Lin, R. Trouillon, M. I. Svensson, J. D. Keighron, A.-S. Cans, and A. G. Ewing, "Carbon-ring microelectrode arrays for electrochemical imaging of single cell exocytosis: fabrication and characterization," Analytical chemistry, vol. 84, no. 6, pp. 2949-2954, 2012.

[3] N. Xiao and B. J. Venton, "Rapid, sensitive detection of neurotransmitters at microelectrodes modified with self-assembled SWCNT forests," Analytical chemistry, vol. 84, no. 18, pp. 7816$7822,2012$.

[4] Z. Dong, U. C. Wejinya, and I. H. Elhajj, "Fabrication and testing of isfet based $\mathrm{pH}$ sensors for microliter target solutions," Sensors and Actuators A: Physical, vol. 194, pp. 181-187, 2013.

[5] S. Chen, Q. Yang, H. Xiao, H. Shi, and Y. Ma, "Local pH monitoring of small cluster of cells using a fiber-optic dual-core micro-probe," Sensors and actuators B: Chemical, vol. 241, pp. 398-405, 2017.

[6] S. R. Ng and D. O'Hare, "An iridium oxide microelectrode for monitoring acute local pH changes of endothelial cells," Analyst, vol. 140, no. 12, pp. 4224-4231, 2015.

[7] X. Liu, Z. A. Wang, R. H. Byrne, E. A. Kaltenbacher, and R. E. Bernstein, "Spectrophotometric measurements of $\mathrm{pH}$ in-situ: laboratory and field evaluations of instrumental performance," Environmental science \& technology, vol. 40, no. 16, pp. 5036-5044, 2006.

[8] M. Şen, K. Ino, H. Shiku, and T. Matsue, "A new electrochemical assay method for gene expression using hela cells with a secreted alkaline phosphatase (seap) reporter system," Biotechnology and bioengineering, vol. 109, no. 8, pp. 2163-2167, 2012.

[9] M. Şen and A. Demirci, "pH-dependent ionic-current-rectification in nanopipettes modified with glutaraldehyde cross-linked protein membranes," RSC advances, vol. 6, no. 89, pp. 86 334-86339, 2016.

[10] M. Sen, "Using electropolymerization based doping for electroaddressable functionalization of a multi-electrode array probe for nucleic acid detection," Analytical Sciences, p. 18P324, 2019.

[11] A. Bayram, M. Serhatlioglu, B. Ortac, S. Demic, C. Elbuken, M. Sen, and M. E. Solmaz, "Integration of glass micropipettes with a $3 \mathrm{~d}$ printed aligner for microfluidic flow cytometer," Sensors and Actuators A: Physical, vol. 269, pp. 382-387, 2018.

[12] M. Sen, Y. Takahashi, Y. Matsumae, Y. Horiguchi, A. Kumatani, K. Ino, H. Shiku, and T. Matsue, "Improving the electrochemical imaging sensitivity of scanning electrochemical microscopy-scanning ion conductance microscopy by using electrochemical Pt deposition," Analytical chemistry, vol. 87, no. 6, pp. 3484-3489, 2015.

[13] M. Sen, "Development of carbon-fiber electrodes modified for electrochemical ATP detection," arXiv preprint arXiv:1810.06967, 2018.

[14] V. K. Aydin and M. Şen, "A facile method for fabricating carbon fiberbased gold ultramicroelectrodes with different shapes using flame etching and electrochemical deposition," Journal of Electroanalytical Chemistry, vol. 799, pp. 525-530, 2017.

[15] H. Kaden, H. Jahn, and M. Berthold, "Study of the glass/polypyrrole interface in an all-solid-state pH sensor," Solid State Ionics, vol. 169, no. 1-4, pp. 129-133, 2004.

[16] M. Etienne, J.-P. Moulin, and S. Gourhand, "Accurate control of the electrode shape for high resolution shearforce regulated secm," Electrochimica acta, vol. 110, pp. 16-21, 2013.

[17] J. Chu, Y. Zhao, S.-H. Li, H.-Q. Yu, G. Liu, and Y.-C. Tian, "An integrated solid-state $\mathrm{pH}$ microelectrode prepared using microfabrication," Electrochimica Acta, vol. 152, pp. 6-12, 2015. 